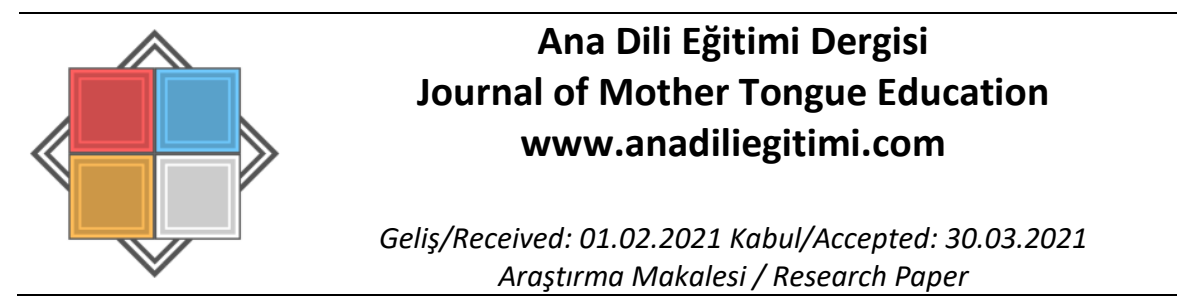

\title{
Ortaokul Türkçe Ders Kitaplarında Haber Bültenlerinde En Sık Kullanılan İlk 2.000 Söz Varlığı Unsurunun Yer Alma Durumu
}

\author{
Bülent Kahraman ÇOLAKOĞLU*
}

\begin{abstract}
Öz
Bu çalışma, MEB'in yayımladığı ortaokul Türkçe ders kitaplarında, haber bültenlerinde en sık kullanılan ilk 2.000 söz varlığı unsurunun [temel kelimeler (isimler, isim soylu kelimeler; fiiller, fiil soylu kelimeler; görevli kelimeler, anlamlı-görevli kelimeler), deyimler, ikilemeler, kalıp sözler] yer alma durumunu belirlemek amacıyla yapılmıştır. MEB Talim ve Terbiye Kurulunun 28.05.2018 - 78, 25.06.2018 - 12254648 tarih ve saylı kararlarıyla kabul edilen, MEB yayınları arasında yer alan ve ortaokullarda okutulan 5, 6, 7 ve 8 . sınıf Türkçe ders kitapları ile haber bültenlerinde en sık kullanılan ilk 2.000 söz varlığı unsurunun sıralandığı liste bu araştırma kapsamında inceleme, değerlendirme ve karşılaştırmaya tabi tutulmuştur. Bir durum çalışması olan bu araştırmada bütüncül çoklu durum deseninden yararlanılmıştır. Doküman incelemesi, veri toplama aracı olarak kullanılmış; elde edilen verilerin anlamlandırılması sürecinde içerik analizi uygulanmıştır. Araştırma sonucunda dört sınıf düzeyindeki Türkçe ders kitabında da öğrencilerin, haber bültenlerinde en sık kullanılan ilk 2.000 söz varlı̆̆ı unsurunun yaklaşık dörtte üçüyle muhatap olduğu, dörtte biriyle de karşılaşmadığı tespit edilmiştir.
\end{abstract}

Anahtar Kelimeler: Söz varlığı, Türkçe ders kitabı, haber bültenleri

\section{Appearance of The First Most Frequently Used 2000 Elements of Vocabulary in News Bulletins in The Textbooks of Turkish Courses in Middle Schools}

\section{Abstract}

This study was conducted with the objective to determine the situation of the appearance of the first most frequently used 2000 elements of vocabulary [basic words (names, nominal words; verbs, gerundial words; postpositions, exclamations), idioms, reduplications, formulaic expressions] in news bulletins, in the textbooks of Turkish courses in middle schools published by the Ministry of Education. The list of first most frequently used 2000 elements of vocabulary in textbooks of Turkish courses taught in the $5^{\text {th }}, 6^{\text {th }}, 7^{\text {th }}$ and $8^{\text {th }}$ grades of middle schools accepted by the resolutions of the Board of Education and Discipline dated and numbered 28.05.2018 - 78, and 25.06.2018 - 12254648, and published by the Ministry of Education has been studied, evaluated and compared within the scope of this study. As a case study, the holistic multiple-case study design was utilized in this research. Document analysis was used as a means of data gathering; and content analysis was implemented during the process of interpreting the acquired data. As a result of the research, it was determined that students have dealt with approximately three quarters of the first most frequently used 2000 elements of vocabulary in news bulletins, in textbooks of Turkish courses in the four grade levels, while a quarter of them have not been encountered.

Key Words: Vocabulary, textbook of Turkish course, news bulletins

\footnotetext{
* Araştırmacı, Türkiye Radyo Televizyon Kurumu, Eğitim ve Araştırma Dairesi Başkanlığı, Ankara, bkcolakoglu@gmail.com, ORCiD: 0000-0001-8321-4204
} 


\section{Giriş}

Söz varlığı kavramı, bilimsel süreç içinde farklı adlandırmalarla kullanılmış ve aynı zamanda araştırmacıların ilgi alanlarına göre de birçok tanımı yapılmıştır. Bu araştırma, belirtilen kavram ve tanımlardan ziyade söz varlığının öğretimine odaklanmaktadır.

Söz varlı̆̆ı terimi için Türkçe Sözlük'te "Bir dildeki sözlerin bütünü, söz hazinesi, söz dağarcığı, sözcük hazinesi, kelime hazinesi, kelime kadrosu, vokabüler." karşılıkları verilmiştir (TDK, 2011, s. 2158). Baş ve Karadağ’a (2012) göre söz varlığı, neredeyse tamamı eş anlamlı olan bu karşılıklardan daha geniş bir kavramdır ve bunların hepsini toplayan en üst aşamadır.

Aksan'a (2015a, s. 15) göre söz varlığı, bir dildeki kelimelerin, deyimlerin, ikilemelerin, kalıp sözlerin, kalıplaşmış sözlerin, atasözlerinin, terimlerin ve çeşitli anlatım kalıplarının oluşturduğu bütündür. Söz varlığı, aynı zamanda o dili konuşan milletin maddi ve manevi kültürünü, dünya görüşünü, yaşam koşullarını ve deneyimlerini de yansıtır (Aksan, 2006, s. 13). Hakkında hiçbir bilgiye sahip olunmayan bir ülkeye ait dilin söz varlığının incelenmesiyle o dili konuşan milletin tarihî ve kültürel gelişimi hakkında genel bilgilere ulaşılabilir. O milletin yaşayış biçimi, inançları, gelenekleri, toplumda önem verilen kavramlar, tarih boyunca ortaya çıkan çeşitli değişmeler ve o toplumun pek çok özelliği öğrenilebilir (Aksan, 2004, s. 179). Yani bir toplumun kültürü ve tarihsel gelişim süreci dil çalışmaları üzerinden takip edilebilir. Çünkü kültür, bütün bileşenleriyle dilde yaşar; varlığını dil sayesinde korur, dille taşınır ve yayılır.

Her toplum, etrafındaki varlıkları ve olayları kendine göre adlandırır ve özümser. Bu yönüyle toplumlar, anlam evrenlerini kendilerine özgü bir yorumla oluştururlar. İnsanın, doğup büyüdüğü çevre şartları insanı etkilerken onun dilini de şekillendirir. Dil, o çevrede yaşayan ve o dili konuşan insanların bakış açıları doğrultusunda oluşturulan göstergelerle biçimlenir (Mert, 2011). Bir milletin kavramlar dünyası onun dünyaya bakış açısını da gösterir. Söz varlığının millette oluşturduğu mevcudiyet, binlerce yıllık kültür birikimini de taşır. Millete mensup her fert bu birikimle yoğrulur. Bununla yetinmeyip bu birikimi çoğaltıp zenginleştirir (Baş, 2006, s. 104). Bir millete ait söz varlığı, o milleti oluşturan fertlerin anlama ve anlatma becerilerinde ulaştığı düzeyin de göstergesi olarak değerlendirilebilir. Çünkü söz varlığının zengin ya da fakir oluşu, anlamayı ve anlatmayı doğrudan etkiler.

Söz varlı̆̆ı, işleyiş yönünden edilgin (pasif, alıcı) kelimelerden (dinlerken ve okurken anlaşılanlar) ve etkin (aktif, üretici) kelimelerden (konuşurken, yazarken kullanılanlar) oluşur. Edilgin söz varlığı, etkin söz varlığına göre daha zengindir. Çünkü insan; pek çok farklı konuda gerçekleştirdiği dinleme ve okuma eylemleri neticesinde edindiği dil birimlerinden, sadece uğraşı ve ilgi alanları doğrultusunda bir kısmını kullanır (Göğüş, 1978, s. 360-361; Özbay ve Melanlıoğlu, 2008; Yalçın, 2012, s. 59). Edilgin söz varlı̆̆ıyla etkin söz varlığı arasındaki fark büyük olmamalıdır. Çünkü böyle bir durum; anlama yönelik dil becerilerini güçlü kılarken anlatıma yönelik dil becerilerinin zayıf olmasına neden olur. Yani dinlediğini ve okuduğunu anlayan ama derdini anlatamayan insan tipi yetiştirilir. Oysa Demir (2006); bir kişinin, edindiği birikimi aktarabilmesi için etkinleştirilmiş bir söz varlığına ihtiyacı olduğunu; paylaşılmayan birikimin ise toplumsal açıdan hiçbir değerinin olmadığını ifade eder. Dilin dinleme ve okuma becerileri ile oluşan edilgin söz varlığıyla sezmek, kavramak, anlamak, öğrenmek, bilmek intiyaçları giderilirken konuşma ve yazma becerileri ile oluşan etkin söz varlığıyla da bilgi vermek, izah etmek, nakletmek ihtiyaçları karşılanır. Edilgin ve etkin söz varlığı birbirinin tamamlayıcısıdır. Her ikisi birden ilişki kurmanın, anlaşmanın, gelişmenin, üretmenin, sosyalleşmenin ve medeniyet oluşturmanın sağlayıcısıdır.

Dil öğretimi, temelde anlama ve anlatma becerilerini kazandırmaya yönelik sistematik faaliyetler bütünüdür. Anlama, yazıda veya konuşmada ne demek istendiğini algılamaktır; okuma ve dinleme faaliyetinin amacıdır. Anlamın belirtileri kelimelerdir. Okuyucu/dinleyici bir yazıyı/konuşmayı onun kelimeleri üzerinde daha önce edindiği bilgilerle anlar. Anlatma; duygu, düşünce, tasarım ve yaşantıların sözle veya yazıyla aktarımıdır. Kişi, bunu yaparken zihinde düşüncelerini belirler, düzenler; seçtiği kelimelerle cümleler kurar, etkili anlatım yolları arar. Anlamlarıyla birlikte öğrenilecek çok sayıda kelimeyle oluşturulacak zengin bir söz varlığı sayesinde anlama ve anlatma becerileri geliştirilip etkinleştirilebilir (Göğüş, 1978, s. 71-74, 167). Temel dil becerilerini ustaca kullanma mahareti kazandırılan bireyin; insanı ve yaşamı anlaması, anlatması, kendini ve hayatını yönetmesi, etkili iletişim kurması ve toplum içinde başarılı bir lider olarak rol alması sağlanabilir. 
Söz varlı̆ı̆ı zenginleştirmek amacıyla eğitim öğretim ortamlarında; sözlükten bulma, bağlamdan anlam çıkarma, kelimeyi cümle içinde kullanma, deyim ve atasözlerinden yararlanma gibi geleneksel yöntemlere başvurulmaktadır. Bununla birlikte bilmece, bulmaca, tekerleme ve şarkılardan istifade etme, karışık olarak verilen harflerden kelime oluşturma, kelime-anlam ve kelime-görsel eşleştirme, kavram ve anlam haritalarından faydalanma, çağrışım çalışmaları yapma gibi çağdaş yöntemler de sıklıkla tercih edilmektedir. Önemli olan söz varlığı edindirme sürecinin, eğitim politikası hâline getirilmesi ve erken dönemden başlatılarak dört temel dil becerisinin eş güdümlü geliştirilmek suretiyle düzenli ve sürekli olarak yürütülmesidir. Çünkü özellikleri itibarılla birbirinin içine girip karışmış bu becerilerden birinin gelişimi, ötekinin gelişimine katkıda bulunmaktadır. Okul öncesi eğitim yıllarında daha çok dinleme ve konuşma becerilerine dayalı söz varlığı oluşur. Okuma ve yazma becerisi henüz kullanılamadığından bireyin bu yollarla kelime öğrenimi gerçekleşmez. Yapılan sözlü tartışmalar, çocuğa görelik ilkesi dikkate alınarak yetişkinler tarafından gerçekleştirilen okuma eylemleri çocukların kelimelere odaklanmasını sağlayan önemli etkinliklerdir. Okuma ve yazma becerileriyle ilgili öğrenim süreci tamamlandığında da okuma ve yazma etkinliklerine yeteri kadar zaman ayrılarak bu becerilere dayalı söz varlığı çoğaltılır.

Sahip olunan söz varlığı ile okuma başarısı arasında doğru orantılı bir ilişki vardır. Söz varlığı yetersiz olanlar bir taraftan gittikçe güçleşen metinleri okumakta zorluk yaşarken diğer taraftan da okuma becerileri zayıf olduğu için söz varlıkları nitel ve nicel olarak sınırlı kalmaya devam etmektedir. Yapılan araştırmalara göre planlı öğretimin dışında bireylerin söz varlı̆ıını zenginleştirmede en kolay, en etkili ve en zevkli yol okumadır (Akyol ve Temur, 2014, s. 198; Yaylamaz, 2014, s. 101). Zengin söz varlığına bağlı olarak okuduğunu kavrayan bireylerin bilgi ve kültür düzeyleri artmakta öğrenmeleri kolaylaşmaktadır (Karatay, 2014, s. 12). Okuma, söz varlığının zenginleşmesi ve düşünce becerilerinin gelişmesi ile birlikte diğer dil becerilerini de olumlu yönde etkiler (Kantemir, 1997, s. 24; Sarıca ve Gündüz, 1999, s. 93-94; Karaalioğlu, t.y., s. 79-80). Nitelikli okuma ve dinleme etkinlikleriyle yeni kelimeler öğrenilerek söz varlığııı geliştirilmesi sağlanır. Konuşma veya yazma becerisiyle herhangi bir anlatım gerçekleştirilmek istendiğinde de çeşitli kelimelere intiyaç duyulur. Böylece daha önce okuma ya da dinleme yoluyla edinilen kelimelerin bellekten çağrılarak kullanılması gerekir (Çiftçi ve Çeçen, 2013). Anlam olarak ilişkili kavramlar, dolayısıyla bu kavramları karşılayan kelimeler zihinde birlikte depolanır. Sık kullanılan kelimeler daha kolay ve uzun süreli depolanırken bunlarla ilgili çağrışım çok daha kolay ve hızlı olur (Akyol ve Temur, 2014, s. 203). Bu durum, söz varlığı ile dil becerilerinin etkili bir şekilde kullanılması arasında güçlü bir bağ olduğunu gösterir. Çok kelime bilmek ve bunların çeşitli anlamlarına vâkıf olmakla dil becerilerinin geliştirilip yetkinleştirilmesi arasında doğrudan ve sıkı bir ilişki vardır.

Geniş bir söz varlığına sahip olan birey, zengin bir kavram dünyası oluşturabilir; duygu ve düşüncelerini açık, akıcı, tutarlı bir şekilde ifade edebilir. Aksi takdirde anlatmak istediklerini tam ve doğru olarak yansıtamaz. İster sözlü ister yazılı anlatımda iletinin, hedef kitleye amaca uygun şekilde ulaştırılması söz varlığına bağlıdır. Yetkin söz varlığı, anlama ve anlatma becerilerinin işlevsel olarak kullanılabilmesinin olmazsa olmazıdır (Göçer, 2009). Temel dil becerileriyle amaçlanan genel olarak anlamak ve anlatmaksa bu becerilerin temel değişkenlerinden biri söz varlığıdır. Dolayısıyla söz varlı̆ı̆ hem nicelik hem de nitelik bakımından planlı ve sürekli olarak zenginleştirilmelidir. Bunun için kişinin, erken yaşlardan başlayarak titizlikle programlanmış iyi bir ana dili eğitimi alması gerekmektedir. Ana dilini kullanmada üst düzey yeterliliğe ulaşan birey, anlamları ve değerleri iyi bilinen kelimelerden meydana gelmiş zengin bir söz varlığını; bu kelimelerle çok sayıda ve çeşitli cümleler kurma yeteneğini kazanmış demektir (Özön, 1971, s. 74). Anlamlarıyla birlikte çok kelime bilmenin, bunları yerinde ve doğru kullanmanın; bireyin dil becerilerini etkili bir şekilde kullanmasında belirleyici bir rolü vardır. Bu nedenledir ki bireylerin söz varlığını zenginleştirerek onların duygu ve düşünce evrenlerini genişletmek; yorum kabiliyetlerini güçlendirmek Türkçe öğretiminin genel amaçlarından biri olarak belirlenmiştir (Sever, 2011, s. 6-7). Bundan dolayı söz varlığını planlı bir biçimde zenginleştirmeye, dört temel dil becerisini kullandırarak geliştirmeye yönelik eğitim öğretim planlamaları yapılmalı, ortamları oluşturulmalıdır.

Birey, kendi ailesinden ve yakın çevresinden kazandığı kelimelere daha sonra çeşitli öğrenmeler ve kaynaklar yoluyla yenilerini katarak söz varlığını giderek zenginleştirir. Aksan’a $(2011$, s. 75) göre ana 
dilini edinmekte olan insan, önceleri tek tek kelimelerden hareketle söz varlığını kazanmaya, giderek onu genişletmeye başlar. Bireyin okul öncesi eğitim ve okul türü öğrenme döneminde, çalışma hayatında, yaşam boyu öğrenme sürecinde yeni yeni kavramlarla karşılaşması, söz varlığının daha da zenginleşmesini sağlar.

Zengin bir söz varlığı, insan ilişkileri ve öğrenme başarısı bakımından da üstünlük vesilesidir. Duygu ve düşüncelerini uygun kelimelerle anlatan kişi başkalarıyla daha sağlıklı ve etkili ilişkiler kurabilir (Kavcar, Oğuzkan ve Sever, 1998, s. 7). Söz varlığı yeterince gelişmemişse bireyin, dinlediğini veya okuduğunu anlaması; anladığını anlatması zordur (Güleryüz, 2006, s. 11). Kavramsal yönden eksik olan bireyler; kendilerini iyi ifade edememekte anlatılanları da tam olarak anlayamamaktadır (Özbay ve Melanlıoğlu, 2008). Oysa zihinde depolanan kavramların ve onları karşılayan kelimelerin sayısı ne kadar çok olursa kişinin dinlediklerini ve okuduklarını anlaması, konuşarak veya yazarak kendini ifade etmesi o denli nitelikli ve kolay olur. Innsanın; zengin bir kavram ve kelime birikimine sahip olması, çok yönlü ve etkili düşünebilmesinin göstergesidir. Söz varlığının zenginliği, anlama ve anlatma yeteneğinin belirleyici unsurlarındandır. Zengin bir söz varlı̆ına sahip kişi; genel olarak çok okuyan, çok kavram tanıyan, çok bilgisi olan, kolay iletişim kuran, anlama ve anlatma becerilerini etkili kullanan kişidir. Bu özelliklere sahip bireylerin yetiştirilmesi tüm ileri toplumların ortak amacıdır. Bir ülkenin gelişmesi, vatandaşlarına yüksek kaliteli yaşam standartları sunabilmesi ancak ifade edilen yeterlikleri edinmiş insanların yapılandırdığı toplum sayesinde mümkün olabilir.

Dillerin zenginliği; duygu, düşünce, kavram, durum ve yaşantıların ayrı ayrı kelimelerle karşılanabilmesi, kelime üretme yetkinliğinin bulunması, geniş bir söz varlığına sahip olunması ve anlatım gücünün yüksekliği ile ölçülür. Bu açıdan bakıldı̆̆ında kökleri tarihin en eski dönemlerine kadar uzanan, günümüzde de geniş bir coğrafyada konuşulan Türkçe, oldukça zengin bir dildir. Bu zenginliği belirleyen en başat ölçütlerden biri söz varlığıdır. Bu nedenle dil öğretimi çalışmaları yapılırken söz varlığını zenginleştirmeye ayrı bir önem verilir. Çeçen'e (2007) göre söz varlığını zenginleştirmenin amacı tam ve etkili iletişim kurmaktır. Doğru telaffuz edilmeyen, doğru yerde kullanılmayan, doğru yazılmayan bir kelimenin iletişime katkı sağlaması beklenemez. Yaşanılan iletişim çağında söz varlığı ne kadar geniş olursa o kadar kazançlı çıkııı; çünkü bir dilin konuşulup yazıldığı kültür ortamı, ticari piyasa gibidir. Bu piyasada sadece kelimelerle alışveriş yapılır. Çok sayıda kelimeye sahip olanın alışverişi de çok olur. Bu piyasada elde edilecek kâr, bilinen kelime sayısıyla doğru orantılıdır. Kültürün ve bilginin toplumda yoğrulup olgunlaştırılması ile sosyal gelişmeler böyle bir hareketlilik içinde gerçekleşir (Demir, 2006). Dolayısıyla kişinin bilgi, beceri kazanması ve toplumun geliş̧mesi etkili iletişime bağlıdır; etkili iletişim de bütün bileşenleriyle birlikte resmî standart dilin ustaca kullanılmasını gerektirir.

Yaratılıp yeryüzüne indirildiği günden bu yana insanoğlunun kurduğu tüm medeniyetler, üretilen bütün maddi ve manevi değerler kuşaktan kuşağa aktarılan birikim sayesinde var olmuştur. Birikim, ömür boyu çeşitli yollarla elde edilen tüm bilgi, beceri ve deneyimlerin toplamıdır (Demir, 2016). Bir insanın, uzun yıllar ve uğraşlar sonucu sahip olduğu birikimi bir başkasına aktarabilmesi için edindiği zengin söz varlığını etkin bir biçimde kullanması gerekir. Bu birikimi aktaracak ve bundan yararlanacak bireylerin kelime hazinelerinin genişliği ile buna bağı olarak dil becerilerini kullanma yeterlilik düzeyleri birbirine yakın olmalıdır. Çünkü sözü edilen alışverişin yapılması ve etkileşimin gerçekleşmesi buna bağlıdır. Sonuç olarak doğru ve etkili iletişim için zengin söz varlığına; insanlık tarihinin ardışık tekâmül sürecinin devamlılığı için de iletişimin zenginliğine ihtiyaç vardır.

Illetişimin son derece yaygın ve vazgeçilemez bir olgu olduğu günümüzde, anlamak ve anlaşılmak ancak ortak kavram ve söz varlığı dünyasına sahip olmakla mümkündür. O nedenle kamu kurumlarında kullanılan dil ile basın yayın organlarında kullanılan dil, o ülkede halk tarafından en çok kullanılan kelimeler hesap edilerek oluşturulmalıdır. Bir ülkedeki ulusal basında kullanılan dilin, o ülke vatandaşları tarafından bilinen ve en çok kullanılan kelimelere bağlı olarak düzenlenmesi ortak söz varlığı oluşturmanın stratejik önemini göstermektedir (Kurudayıoğlu, 2011). Zira basın yayın organlarında kullanılan dil, bütün unsurlarıyla topluma hitap eder ve doğal akışına uygun şekilde iletişim sürecinin tamamlanmasını destekler. Bu nedenle gelişmiş toplumlarda genel okur/dinleyici/izleyici kitlesine yönelik hazırlanan basın yayın içerikleri temel eğitim okullarından mezun olan bireylerin zorlanmadan anlayabilecekleri biçimde düzenlenir. Çünkü ortak bir kelime evreni; toplumu meydana getiren fertlerin sağlam ve güvenilir iletişim kurmaları, birbirlerini tam ve 
doğru anlamaları, toplumu ilgilendiren olumlu ya da olumsuz olaylar karşısında benzer duygu ve düşünceleri paylaşıp ortak tepkiler verebilmeleri için elzemdir.

Ülkemizde ortak söz varlığı oluşturmak için ihtiyaç duyulan, yaş aralıklarına veya sınıf seviyelerine göre çocuklara öğretilmesi gereken dil birimlerinin yer alacağı listeler henüz oluşturulmamıştır. Oysa Batı'da söz varlığıyla ilgili araştırmalar yaklaşık 100 yıldır yapılmaktadır. Bu çalışmalarla düzeylere göre belirlenen kelime listeleri, iletişimde en sık kullanılan kelimeler göz önünde bulundurularak güncellenmektedir. Çünkü bir dilde en sık kullanılan ilk 1.000 ila 2.000 kelimeyi anlamlarıyla birlikte bilmenin toplumun geneline hitap eden bir metnin yaklaşık \%90'ını anlamak olduğuna dikkat çeken çeşitli görüşler mevcuttur. Aksan (2015b, c. III, s.20), bir dilde en sık kullanılan 1.000 kelimeyle normal metinlerin \%80'inden fazlasının, 2.000 kelimeyle \%88 ila \%90'ının anlaşılabildiğini belirtmektedir. Bauman (1996), sıklığı en yüksek ilk 2.000 kelimenin ortalama bir yazılı metnin \%87'sini oluşturduğunu ifade etmektedir. Demek ki bir dilde en sık kullanılan ilk 2.000 kelimeyi bilmek ve bunları etkin söz varlığı unsuru hâline getirmek, ortak bir kelime hazinesiyle sağlıklı bir iletişim ve etkileşim sürecini işletmenin gereğidir.

Türkçe eğitiminin amaçlarına ulaşmak için genelde kullanılan en yaygın, en işler ve en etkili araç ders kitaplarıdır. Bu kitaplardaki metinlerin, millî stratejik dil öğretimi hedeflerine göre belirlenecek ortak söz varlığı unsurlarıyla örülmesi lazımdır. Bu, ortak söz varlığı oluşturmak için en temel şartlardan biri olarak değerlendirilmelidir. Ancak yaş gruplarına veya sınıf düzeylerine göre öğrencilere kazandırılacak söz varlığı listeleri henüz ortaya konulamadığından ders kitapları, bu yönüyle eksik ve yetersiz kalmaktadır.

Toplumu oluşturan tüm bireylere kültürümüzün aktarılıp benimsetilmesi, her biri kültürel bir hazine değeri taşıyan ortak söz varlığı unsurlarının kazandırılması, resmî standart dilin doğru ve güzel kullanılmasının öğretilmesi amacıyla okul öncesi dönemden başlayarak her yaş grubundaki kişilere, edindirilecek söz varlığı unsurlarının ilgililerce bilinmesi gerekmektedir. Bunun için ihtiyaç duyulan çalışmalar yapılmalı, her seviyeye uygun söz varlığı unsurlarını içeren listeler Millî Eğitim Bakanlığı tarafından oluşturulmalıdır. Söz konusu listeler, ders kitabı yazım sürecinde başvurulması gereken belli başlı kaynaklar arasında bulunmalıdır. Yapılacak eğitim öğretim etkinlikleri, basın yayın hizmetleri vb. toplumu ilgilendiren anlama ve anlatmayla ilgili faaliyetler, bu listelerdeki söz varlığı unsurlarının kullanımına öncelik verilmek suretiyle ortak söz varlı̆̆ı etkinleştirilerek gerçekleştirilmelidir.

Ülkemizde söz varlığı üzerine son yıllarda yapılan araştırmalar hem nicelik hem nitelik yönünden farklı bir boyut kazanmıştır. 2015 yılında TRT 1'de bir yıl boyunca yayımlanan, tüm ana haber bültenlerini içeren, 1.495.416 kelimelik ham metin havuzu üzerinde söz varlığı unsurlarının tespitine dair titiz çalışmalar gerçekleştirilmiştir. Bu çalışmalar sonucunda ortaya çıkarılan sıklık listelerinden ${ }^{* *}$ biri Haber Bültenlerindeki illk 2.000 Söz Varlığı Unsuru adlı listedir. MEB'in yayımladığı ortaokul Türkçe ders kitaplarında, söz konusu listedeki dil birimlerinin [temel kelimeler (isimler, isim soylu kelimeler; fiiller, fiil soylu kelimeler; görevli kelimeler, anlamlı-görevli kelimeler), deyimler, ikilemeler, kalıp sözler] yer alma durumunu belirlemek için yapılan bu araştırmada aşağıdaki soruların cevapları verilmeye çalışılmıştır:

1. MEB 5. sınıf Türkçe ders kitabında, haber bültenlerinde en sık kullanılan ilk 2.000 söz varlığı unsurunun yer alma durumu nedir?

2. MEB 6. sınıf Türkçe ders kitabında, haber bültenlerinde en sık kullanılan ilk 2.000 söz varlığı unsurunun yer alma durumu nedir?

3. MEB 7. sınıf Türkçe ders kitabında, haber bültenlerinde en sık kullanılan ilk 2.000 söz varlığı unsurunun yer alma durumu nedir?

4. MEB 8. sınıf Türkçe ders kitabında, haber bültenlerinde en sık kullanılan ilk 2.000 söz varlığı unsurunun yer alma durumu nedir?

5. MEB ortaokul Türkçe ders kitaplarında, haber bültenlerinde en sık kullanılan ilk 2.000 söz varlığı unsurunun yer alma durumu nedir?

\footnotetext{
** Bülent Kahraman Çolakoğlu tarafından hazırlanan, savunma aşamasında olan Haber Bültenlerindeki Söz Varlığı Üzerine Bir Araştırma adlı doktora tezine ait bulgulardan söz edilmektedir.
} 


\section{Araştırmanın Modeli}

\section{Yöntem}

Bir durum çalışması olan bu araştırmada bütüncül çoklu durum deseninden yararlanılmıştır. Durum çalışması; nitel araştırmalarda yaygın olarak tercih edilen, farklı biçimleri olan bir yaklaşımdır. Davey'e (1990) göre bir durum ya da olayın derinlemesine ve boylamsal olarak incelendiği bir yöntemdir. Araştırmaya konu edilen durumu betimlemenin, ayrıntılı veri toplamanın, bilgileri analiz etmenin ve sonuçları raporlamanın sistematik bir yoludur. Bu çalışmada birden çok durumdan bahsetmek mümkündür. Her bir durum, kendi içinde bütüncül bir yaklaşımla incelendiği ve ulaşılan sonuçlar birbirleriyle karşılaştırıldığı için (Yıldırım ve Şimşek, 2013, s. 327) bütüncül çoklu durum deseni kullanılmıştır. Anılan deseni; MEB ortaokul Türkçe ders kitaplarında, haber bültenlerinde en sık kullanılan ilk 2.000 kelimenin yer alma durumu ve elde edilen verilerin birbirleriyle kıyaslanması durumu oluşturmuştur.

\section{İnceleme Nesneleri}

MEB Talim ve Terbiye Kurulunun 28.05.2018 - 78, 25.06.2018 - 12254648 tarih ve sayılı kararlarıyla kabul edilen, MEB yayınları arasında yer alan, ortaokullarda okutulan Ortaokul ve İmam Hatip Ortaokulu Türkçe 5 Ders Kitabı, Ortaokul ve Imam Hatip Ortaokulu Türkçe 6 Ders Kitabı, Ortaokul ve İmam Hatip Ortaokulu Türkçe 7 Ders Kitabı, Ortaokul ve İmam Hatip Ortaokulu Türkçe 8 Ders Kitabı ile Haber Bültenlerindeki İlk 2.000 Söz Varlığı Unsuru sıklık listesi bu araştırmanın inceleme nesnelerini teşkil etmektedir. Sözü edilen ders kitaplarındaki iç kapak, bibliyografik künye, İstiklal Marşı, Gençliğe Hitabe, içindekiler, organizasyon şeması, kaynakça, cevap anahtarı ve sözlük bölümleri bütün ders kitaplarında bulunduğu ve direkt ders konusu olmadığı için araştırmaya katılmamıştır. Bu bölümlerdeki dil birimleri dışında ders kitaplarındaki bütün söz varlığı unsurları incelemeye dâhil edilmiştir.

\section{Verilerin Toplanması ve Analizi}

Veriler, doküman incelemesi yöntemiyle toplanmıştır. Doküman incelemesi, araştırılmak istenen olgu veya olgularla ilgili bilgi içeren yazılı materyallerin analizini kapsar (Yıldırım ve Şimşek, 2013, s. 217). Verilerin anlamlandırılması sürecinde de temel olarak içerik analizi kullanılmıştır. İçerik analizi; sözel, yazılı ve diğer materyallerin içerdiği iletiyi, anlam ve/veya dil bilgisi açısından nesnel ve sistematik olarak sınıflandırma, sayılara dönüştürme ve çıkarımda bulunma yoluyla sosyal gerçeği araştıran bilimsel bir yaklaşımdır (Tavşancıl ve Aslan, 2001, s. 22). Bu bağlamda bahsi geçen $5,6,7$ ve 8. sınıf Türkçe ders kitapları taranarak Microsoft Office Word belgesi hâline getirilmiştir. Metin dışı unsurların temizlenmesinin ardından Haber Bültenlerindeki Ilk 2.000 Söz Varlığı Unsuru sıklık listesinde bulunan bütün dil birimleri; MEB 5, 6, 7 ve 8. sınıf Türkçe ders kitaplarında ayrı ayrı ve tek tek aratılmıştır. Daha sonra dört ders kitabı bir araya getirilmiş ve haber bültenlerinde en sık kullanılan ilk 2.000 söz varlığı unsuru ortaokul Türkçe ders kitaplarında yeniden aratılmışır.

Haber Bültenlerindeki illk 2.000 Söz Varlığı Unsuru sıklık listesinde yer alan dil birimlerinin 82'si deyim, 6'sı kalıp söz, 4'ü ikileme, 340'ı fiil, 88'i birleşik fiil ve 77'si ayrı yazılan birleşik kelimedir. Geri kalan $1.403^{\prime}$ ü de diğer temel kelimelerdir. Kitaplar üzerinde yapılan inceleme çalışmaları, buradaki sınıflama dikkate alınarak gerçekleştirilmiştir. Böylece araştırmaya ait bulgular elde edilmiştir.

\section{Araştırma ve Yayın Etiği}

Bu çalışmada "Yükseköğretim Kurumları Bilimsel Araştırma ve Yayın Etiği Yönergesi" kapsamında uyulması belirtilen tüm kurallara uyulmuştur. Yönergenin ikinci bölümü olan "Bilimsel Araştırma ve Yayın Etiğine Aykırı Eylemler" başlığı altında belirtilen eylemlerden hiçbiri gerçekleştirilmemiştir.

\section{Bulgular}

Uluslararası Standart Kitap Numarası (ISBN) 978-975-11-4602-1 olan ve 254 sayfadan oluşan MEB 5. sınıf Türkçe ders kitabı toplam 40.508 kelimeden, Uluslararası Standart Kitap Numarası 978975-11-4597-0 olan ve 288 sayfadan oluşan MEB 6. sınıf Türkçe ders kitabı toplam 41.696 kelimeden, Uluslararası Standart Kitap Numarası 978-975-11-4558-1 olan ve 264 sayfadan oluşan MEB 7. sınıf 
Türkçe ders kitabı toplam 46.907 kelimeden, Uluslararası Standart Kitap Numarası 978-975-11-4598-7 olan ve 251 sayfadan oluşan MEB 8. sınıf Türkçe ders kitabı ise toplam 44.699 kelimeden meydana gelmiştir.

Ders kitaplarındaki iç kapak, bibliyografik künye, İstiklal Marşı, Gençliğe Hitabe, içindekiler, organizasyon şeması, kaynakça, cevap anahtarı ve sözlük bölümleri çıkarıldıktan sonra MEB 5. sınıf Türkçe ders kitabındaki 38.171; MEB 6. sınıf Türkçe ders kitabındaki 38.569; MEB 7. sınıf Türkçe ders kitabındaki 43.573; MEB 8. sınıf Türkçe ders kitabındaki 42.350 ve dört ders kitabındaki toplam 162.663 kelime, araştırma verisi olarak incelemeye tabi tutulmuştur.

MEB 5. sınıf Türkçe ders kitabında, haber bültenlerinde en sık kullanılan ilk 2.000 söz varlığı unsurunun 1.422 'si varken 578 'i yoktur.

MEB 6. sınıf Türkçe ders kitabında, haber bültenlerinde en sık kullanılan ilk 2.000 söz varlığı unsurunun $1.508^{\prime} \mathrm{i}$ varken 492 'si yoktur.

MEB 7. sınıf Türkçe ders kitabında, haber bültenlerinde en sık kullanılan ilk 2.000 söz varlığı unsurunun 1.530 ' u varken $470^{\prime} \mathrm{i}$ yoktur.

MEB 8. sınıf Türkçe ders kitabında, haber bültenlerinde en sık kullanılan ilk 2.000 söz varlığı unsurunun 1.466 'sı varken $534^{\prime}$ ü yoktur.

MEB ortaokul Türkçe ders kitaplarında, haber bültenlerinde en sık kullanılan ilk 2.000 söz varlığı unsurunun $1.761^{\prime} i$ varken $239^{\prime}$ u yoktur. Bununla birlikte bu dört ders kitabında, 206 söz varlığı unsurunun sadece bir veya iki defa geçtiği tespit edilmiştir.

\section{Tartışma ve Sonuç}

Dilin ve eğitiminin hayati önem taşıdığının farkında olan gelişmiş ülkeler, resmî standart dil eğitiminde belli bir düzeye ulaşmak isterler. Bunun için de bazı somut hedefler belirlerler. Yalçın'a (2018, s. 113-114) göre toplumu oluşturan bütün bireylerin, basın yayın organlarında kendilerine sunulan haberleri anlayabilecek dil yeterliliğine sahip olması birinci somut hedeftir. Buna haberlerin yorumlandığı köşe yazıları da dâhildir. Zorunlu eğitim sürecini tamamlamış bir öğrencinin kendi ulusal meclisinde ve belediye meclislerinde yapılan konuşmaları, tartışmaları anlayabilmesi ve gerektiğinde görüşlerini ifade edebilmesi de ikinci somut hedeftir. Bu bağlamda basın yayın dili, toplumsal iletişim sürecinin başat unsuru olarak öne çıkmakta; bilgi, haber vb. alışverişi yapmanın, anlaşmanın en işler, en canlı ve en etkili dil düzeyini göstermektedir. Dolayısıyla haber bültenleri üzerinde yapılan bir söz varlığı araştırmasından elde edilen Haber Bültenlerindeki Ilk 2.000 Söz Varlığı Unsuru sıklık listesindeki dil birimlerinin, öğrencilerin söz varlıklarına kazandırılmak üzere Türkçe ders kitaplarında bulunup bulunmadığının ortaya konması; eğitim öğretim faaliyetlerinin düzenlenmesi, nitelikli ders kitapları ile çocuk ve gençlik edebiyatı ürünlerinin hazırlanabilmesi için gereklidir. Dört sınıf düzeyindeki Türkçe ders kitabında da öğrenciler, haber bültenlerinde en sık kullanılan ilk 2.000 söz varlığı unsurunun yaklaşık dörtte üçü ile muhatap olurken dörtte biri ile karşılaşmamaktadır. Bu durumda toplumsal ilişkilerde iletişimden kaynaklı sorunların yaşanma olasılı̆̆ı artacaktır. Çünkü insanların birbirlerini tam ve doğru anlayabilmeleri ancak ortak kavram ve dil birimi evrenine sahip olmalarıyla mümkündür. Bu yüzden ortak söz varlığının stratejik öneminin farkında olan devletler, ulusal basın yayın organlarında kullanılan dilin o ülkede halk tarafından en sık kullanılan söz varlığı unsurları esas alınarak biçimlendirilmesini sağlarlar.

Öğretim programları gereğince yazılan, öğretmen-öğrenci arasındaki iletişimi ve etkileşimi kolaylaştıran, aynı idealler doğrultusunda öğrenmeyi ve gelişmeyi destekleyen, tekrar etme ve bireysel öğrenme imkânı veren, ortak söz varlığı kazandırmada ana gereç değeri taşıyan ders kitapları, ders işlemenin en temel aracıdır. Buna ve yaptığımız araştırmadan elde ettiğimiz verilere göre;

5. sınıf Türkçe dersinde öğrenciler, Haber Bültenlerindeki Ilk 2.000 Söz Varlığı Unsurunun $\% 28,9^{\prime}$ u ile karşılaşmamaktadır.

6. sınıf Türkçe dersinde öğrenciler, Haber Bültenlerindeki ilk 2.000 Söz Varlığı Unsurunun $\% 24,6$ 'sı ile karşılaşmamaktadır.

7. sınıf Türkçe dersinde öğrenciler, Haber Bültenlerindeki Ilk 2.000 Söz Varlığı Unsurunun $\% 23,5^{\prime}$ i ile karşılaşmamaktadır. 
8. sınıf Türkçe dersinde öğrenciler, Haber Bültenlerindeki Ilk 2.000 Söz Varlı̆ı Unsurunun $\% 26,7$ 'si ile karşılaşmamaktadır.

Ortaokul Türkçe derslerinde öğrenciler, Haber Bültenlerindeki ilk 2.000 Söz Varlığı Unsurunun \%11,9'u ile karşılaşmamaktadır. Dört sınıf düzeyindeki Türkçe ders kitabında da ortalama \%25 civarında olan karşılaşılmayan söz varlığı oranı, sözü edilen dört ders kitabı bir Microsoft Office Word belgesi üzerinde bir araya getirildiği durumda yaklaşık \%12 olarak tespit edilmektedir. Buradaki oranlar arasında neredeyse \%50'lik bir fark mevcuttur. Bunun sebebi, Haber Bültenlerindeki ilk 2.000 Söz Varlığı Unsuru sıklık listesindeki bir dil biriminin, bu dört Türkçe ders kitabından herhangi birinde yalnızca bir defa bile geçmesinin, o dil biriminin öğrencilerin ortaokul Türkçe derslerinde karşılaştığı söz varlığı unsurları arasında sayılması için yeterli görülmesidir. Yani 5. sınıf Türkçe ders kitabında yer almayan bir söz varlığı unsuru 7. sınıf Türkçe ders kitabında, 6. sınıf Türkçe ders kitabında yer almayan bir söz varlığı unsuru 8. sınıf Türkçe ders kitabında bulunabilmektedir. Bu da o söz varlığı unsurunun ortaokul Türkçe derslerinde öğrencilerin karşılaştığı dil birimlerinden biri olarak kabul edilmesini sağlamaktadır.

MEB Türkçe 5, 6, 7 ve 8. sınıf Türkçe ders kitaplarında sadece bir veya iki kez geçen söz varlığı unsurları da hesaba katııırsa yukarıdaki oransal sonuçların üzerinde yaklaşık \%10'luk bir artış söz konusu olacaktır. Diğer bir ifadeyle Türkçe ders kitaplarında, haber bültenlerinde en sık kullanılan ilk 2.000 söz varlığı unsurunun ortalama \%25'i ile karşılaşılamazken bu oran, bahis konusu \%10'luk artış ilave edildiğinde \%35 olacaktır. Bu, bir toplum için çok önemli olan ortak kavram ve söz varlığı evreni oluşturma hedefine tam olarak erişilemeyeceğinin, toplumsal iletişim sürecinde meydana gelebilecek önemli eksiklerin ve aksaklıkların işareti olarak değerlendirilebilir.

Ortaya çıkarılan bu oranlara bakıldığında, sınıf seviyesi arttıkça karşılaşılmayan dil birimi sayısının belli oranda azalması gerekirken incelediğimiz ders kitaplarında durumun böyle olmadığı görülmektedir. Ortaokul Türkçe ders kitaplarında karşılaşılmayan dil birimlerinin niceliği bakımından 5 . sınıftan 7. sınıfa doğru bir azalma görülse de bu azalma oransal tutarlılıktan yoksundur. Bununla birlikte karşılaşılmayan söz varlığı unsuru sayısının ortaokulun diğer sınıf düzeylerine göre 8. sınıfta en az olması beklenirken 6 ve 7. sınıftakinden daha yüksek olması dikkat çekicidir. Bu durum, ders kitapları yazııırken öğrencilerin söz varlığını zenginleştirme çalışmalarına ilişkin izlemsel bir planlama yapılmadığını düşündürmektedir. Türkçe ders kitaplarındaki metinlerin söz varlığı yönünden incelenmesi ile ilgili çeşitli üniversitelerde özellikle birçok yüksek lisans tezi yaptırılmıştır. Bu araştırmalar, benzer sonuçları itibarıyla belirtilen düşünceyi desteklemektedir: Türkçe ders kitaplarında dilimizin gücünü ve anlatım olanaklarını yansıtan zengin bir söz varlığına rastlanmamaktadır (Baysal, 2007, s. 1202-1203; Turhan, 2010, s. 466; Yiğit, 2011, s. 184). Öğrencilere kazandırılacak söz varlığı unsurlarıyla ilgili listeler olmadığı için Türkçe ders kitapları hazırlanırken kelime öğretimi ile ilgili belli bir strateji izlenmemekte, metinler aracılığıyla gerçekleştirilen dil çalışmalarında programlı bir kavram ve kelime öğretimi yapılmamaktadır (Apaydın, 2010, s. 335; Aslan, 2013, s. 145-146; Baysal, 2007, s. 1206; Uludağ, 2010, s. 419; Yiğit, 2011, s. 184). Kelime hazinesini geliştirmeye dönük nitelikli metin seçiminde gerekli özen gösterilmemektedir (Apaydın, 2010, s. 337; Baysal, 2007, s. 1205; Turhan, 2010, s. 470-471; Uludağ, 2010, s. 418).

Haber bültenlerinde en sık kullanılan ilk 2.000 söz varlığı unsurunun ortalama 500'ü ortaokul Türkçe ders kitaplarında bulunmamaktadır. Bahse konu söz varlığı unsurlarını içeren listedeki her bir dil biriminin bu dört sınıf seviyesindeki Türkçe ders kitaplarında eksiksiz bulunması da beklenmemektedir. Ancak 5. sınıftan başlayıp 8. sınıfa doğru planlı bir artışla bu söz varlığı unsurlarının tamamına ortaokul Türkçe ders kitaplarında yer verilebilir. Elbette bunun için Millî Eğitim Bakanlığı tarafından bütün sınıf seviyelerine göre söz varlı̆̆ı listelerinin hazırlanmış olması gerekir. Bu söz varlığı listelerine uygun biçimde ders kitabı yazım süreçleri işletilebilir. Böylece millî stratejik eğitim hedefleri doğrultusunda resmî standart dil eğitiminde önemli bir aşama kaydedilebilir.

Temel hak ve özgürlükleri içine alan demokratik bir okul kültürünü benimsetmek, eğitim sistemine yerleştirmek ve toplumu meydana getiren insanlar arasında demokratik kültür uygulamalarını yaygınlaştırmak amacıyla Millî Eğitim Bakanlığı, ilkokul ve ortaokul düzeyinde projeler gerçekleştirmektedir. Ancak haber bültenlerinde sıkça kullanıldığı hâlde ortaokul Türkçe ders kitaplarında yer verilmeyen 239 dil biriminden demokrasi kültürü tamlamasının kavram ve çağrışım alanına giren aşağıdaki söz varlığı unsurları, üzerinde durulmaya değer bir veri olarak belirmektedir. 
"aday adayı, anayasa, atama, basın toplantısı, başkanlık sistemi, denetim, genel başkan, genel merkez, genel seçim, hukuki, hükûmet kur-, istifa et-, kabine, katılım, koalisyon, komisyon, kurultay, milletvekili, mağdur, muhalefet, muhalefet partisi, muhalif, müzakereci, oturum, oy kullan-, oy ver-, oylama, parlamento, propaganda, reform, rejim, sandığa git-, seçim hükûmeti, seçmen, seçmen kütügü, siyasetçi, vekil, vesayet, yasa, yasa dışı, yasal"

Ortaokul sosyal bilgiler veya diğer ders kitaplarında bu söz varlığı unsurlarına rastlanabilse de kelime, kelime grubu ve cümle çalışmalarıyla öğrencilerin söz varlıklarını zenginleştirmek; duygu, düşünce ve hayal dünyalarını geliştirmek, onlara dil zevki ve bilinci kazandırmak Türkçe dersi öğretim programlarının amaçlarındandır. Dolayısıyla bu amaçlara, Türkçe ders kitaplarındaki metinler aracılığıyla ve ilgili kazanımlara yönelik gerçekleştirilecek çalışmalarla ulaşmak gerekir. Bu nedenle demokrasi kültürünün hayata geçirilmesi ve daha güçlü hâle getirilmesi için Türkçe ders kitaplarındaki metinlerin nitelikleri ve çeşitliliği gözden geçirilmelidir.

\section{Araştırma ve Yayın Etiği}

Bu çalışmada "Yükseköğretim Kurumları Bilimsel Araştırma ve Yayın Etiği Yönergesi" kapsamında uyulması belirtilen tüm kurallara uyulmuştur. Yönergenin ikinci bölümü olan "Bilimsel Araştırma ve Yayın Etiğine Aykırı Eylemler" başlığı altında belirtilen eylemlerden hiçbiri gerçekleştirilmemiştir.

\section{Yazarların Katkı Oranı}

Bu makale, yazarın kendisi tarafından tek başına hazırlanmıştır.

\section{Çıkar Çatışması}

Bu araştırmada çıkar çatışması teşkil edebilecek herhangi bir durum ya da ilişki yoktur.

\section{Kaynaklar}

Aksan, D. (2004). Dilbilim ve Türkçe yazılar. İstanbul: Multilingual.

Aksan, D. (2006). Anadilimizin söz denizinde. Ankara: Bilgi.

Aksan, D. (2011). Dil, şu büyülü düzen. Ankara: Bilgi.

Aksan, D. (2015a). Türkçenin söz varlığı. Ankara: Bilgi.

Aksan, D. (2015b). Her yönüyle dil ana çizgileriyle dilbilim. Ankara: TDK.

Akyol, H. ve Temur, T. (2014). Kelime hazinesinin geliştirilmesi. A. Kırkkılıç ve H. Akyol (Ed.), ilköğretimde Türkçe öğretimi içinde (s.193-229). Ankara: Pegem Akademi.

Apaydın, N. (2010). 6. sınıf ders kitaplarının söz varlığı açısından incelenmesi (Yayımlanmamış yüksek lisans tezi). Marmara Üniversitesi Eğitim Bilimleri Enstitüsü, İstanbul.

Aslan, T. (2013). 7. sınıf öğrencilerinin Türkçe ders kitaplarındaki anlamını bilmedikleri kelimelerden hareketle söz varlığını geliştirmelerine yönelik bir araştırma (Yayımlanmamış yüksek lisans tezi). Gazi Üniversitesi Ĕgitim Bilimleri Enstitüsü, Ankara.

Baş, B. (2006). 1985-2005 yılları arasında çocuk edebiyatı sahasında yazılmış tahkiyeli metinlerin söz varlığı üzerine bir araştırma (Yayımlanmamış doktora tezi). Gazi Üniversitesi Eğitim Bilimleri Enstitüsü, Ankara.

Baş, B. ve Karadağ, Ö. (2012). Söz varlığı üzerine yurt dışında ve Türkiye'de yapılan temel araştırmalar. Millî Eğitim. 193, 81-104.

Bauman, J. (1996). Vocabulary Resources for Material Writers. Material Writers Newsletter; Vol. 4, No. 3, October. Erişim Adresi: https://files.eric.ed.gov/fulltext/ED416672.pdf

Baysal, A. D. (2007). ilköğretim 7. sınıf Türkçe ders kitaplarının kelime serveti bakımından değerlendirilmesi (Yayımlanmamış yüksek lisans tezi). Afyon Kocatepe Üniversitesi Sosyal Bilimler Enstitüsü, Afyon.

Çeçen, M. A. (2007). Kelime hazinesinin geliştirilmesinde dikkat edilmesi gereken hususlar. Journal of Turkish Linguistics. 1(1), 116-137.

Çiftçi, Ö. ve Çeçen, M. A. (2013). Kelime öğretimi. A. Güzel ve H. Karatay (Ed.), Türkçe öğretimi el kitabı içinde (s.335-350). Ankara: Pegem Akademi. 
Davey, L. (1990). The application of case study evaluations. Practical Assessment, Research and Evaluation. Vol. 2 , Article 9. DOI: 10.7275/02g8-bb93.

Demir, C. (2006). Türkçe / edebiyat eğitimi ve kişisel kelime serveti. Millî Eğitim. 169, 207-225.

Demir, C. (2016). Türkçe eğitim öğretim programları ve kişisel söz varlığı [Özel Sayı]. Millî Eğitim, 210, 141-161.

Göçer, A. (2009). Türkçe eğitiminde öğrencilerin söz varlığını geliştirme etkinlikleri ve sözlük kullanımı. Turkish Studies. 4 (4), 1025-1055. DOI: 10.7827/TurkishStudies.845.

Göğüş, B. (1978). Orta dereceli okullarımızda Türkçe ve yazın eğitimi. Ankara: Gül.

Güleryüz, H. (2006). Yaratıcı çocuk edebiyatı. Ankara: Pegem A.

Kantemir, E. (1997). Yazılı ve sözlü anlatım. Ankara: Engin.

Karaalioğlu, S. K. (t.y.). Yazmak ve konuşmak sanatı. İstanbul: İnkılap.

Karatay, H. (2014). Okuma eğitimi. Ankara: Pegem Akademi.

Kavcar, C., Oğuzkan, F. ve Sever, S. (1998). Türkçe öğretimi. Ankara: Engin.

Kurudayıoğlu, M. (2011). illköğretim ikinci kademe öğrencilerinin kelime hazinesi üzerine bir değerlendirme. e-Journal of New World Sciences Academy. 6(2), 1797-1808.

Mert, E. L. (2011). Türkçenin söz varlığı açısından 6. sınıf Türkçe ders kitaplarındaki öyküleyici metinler.

S. Sever (Ed.), Prof. Dr. Cahit Kavcar Türkçe eğitimi çalıştayı içinde (s.235-248). Ankara: Ankara Üniversitesi.

Özbay, M. ve Melanlığlu, D. (2008). Türkçe eğitiminde kelime hazinesinin önemi. Yüzüncü Yıl Üniversitesi Eğitim Fakültesi Dergisi. 5(1), 30-45.

Özön, M. N. (1971). Yazmak sanatı ve kompozisyona giriş. İstanbul: Remzi.

Sarıca, S. ve Gündüz, M. (1999). Güzel konuşma yazma, kompozisyon. İstanbul: Fil.

Sever, S. (2011). Türkçe öğretimi ve tam öğrenme. Ankara: Anı.

Tavşancıl, E. ve Aslan, A. E. (2001). Sözel, yazılı ve diğer materyaller için içerik analizi ve uygulama örnekleri. İstanbul: Epsilon.

TDK (2011). Türkçe sözlük. Ankara: TDK.

Turhan, H. (2010). 8. sınıf Türkçe ders kitabındaki metinlerin söz varlığı açısından incelenmesi (Yayımlanmamış yüksek lisans tezi). Marmara Üniversitesi Eğitim Bilimleri Enstitüsü. İstanbul.

Uludağ, Ç. (2010). 7. sınıf Türkçe ders kitaplarının söz varlığı açısından incelenmesi (Yayımlanmamış yüksek lisans tezi). Marmara Üniversitesi Eğitim Bilimleri Enstitüsü, İstanbul.

Yalçın, A. (2012). Türkçe öğretim yöntemleri yeni yaklaşımlar. Ankara: Akçağ.

Yalçın, A. (2018). Son bilimsel gelişmeler ışığında Türkçenin öğretimi yöntemleri. Ankara: Akçağ.

Yaylamaz, S. (2014). Okuma zekâsı. İstanbul: Hayat.

Yıldırım, A. ve Şimşek, H. (2013). Sosyal bilimlerde nitel araştırma yöntemleri. Ankara: Seçkin.

Yiğit, A. (2011). Millî Eğitim Bakanlığı 8. sınıf Türkçe ders kitabındaki metinlerin kelime serveti açısından incelenmesi (Yayımlanmamış yüksek lisans tezi). Atatürk Üniversitesi Eğitim Bilimleri Enstitüsü, Erzurum.

\section{Introduction}

\section{Extended Abstract}

The term vocabulary is defined as "bir dildeki sözlerin bütünü (the entirety of the words in a language), söz hazinesi (vocabulary), söz dağarcığı (vocabulary), sözcük hazinesi (vocabulary), kelime hazinesi (vocabulary), kelime kadrosu (vocabulary), vokabüler (vocabulary)" in the Turkish dictionary (TDK, 2011, p. 2158). According to Baş and Karadağ (2012), it is a more extensive concept than these definitions that are almost synonyms, and is the highest echelon incorporating all of them.

The vocabulary belonging to a nation may be evaluated as the indication of the level of word attack skills that individuals constituting that nation have reached; because richness or poorness of vocabulary directly influences comprehension and narration.

A person with a rich vocabulary is, in general, a person who does much reading, knows many concepts, is knowledgeable, is able to communicate easily, and is able to use word attack skills effectively. Educating individuals with such characteristics is the common objective of all advanced societies. Development of a country, its capability of offering high-quality living standards to its citizens 
is only possible owing to a society structured by people who have acquired the abovementioned characteristics.

The language used in media organs addresses the society with all its constituents and supports the completion of the communication process suitably to its natural flow. For this reason, media contents prepared for the general reader/listener/viewer in developed societies are arranged in a way that individuals that have graduated from primary education schools can understand without difficulty. Because the common universe of words is essential for members that constitute the society can engage in solid and reliable communication, understand one another exactly and accurately, share similar emotions and thoughts on positive or negative events that concern the society and be able to react jointly.

It is essential for those concerned to know the elements of vocabulary that will be provided for individuals of all age groups starting from the preschool period with the objective of conveying and infusing our culture to all individuals who constitute the society, establishing elements of vocabulary that are the indicators of our culture, teaching the Turkish language in the best and most operable way. Therefore, required studies should be conducted and lists containing elements of vocabulary suitable to all levels should be created by the Ministry of Education. Educational activities to be held, and activities related to comprehension and narration of issues concerning the society like media services should be materialized bearing those lists in mind and with the objective of providing a common vocabulary.

The objects of analysis of this study conducted to determine the situation of the appearance of the first most frequently used 2000 elements of vocabulary [basic words (names, nominal words; verbs, gerundial words; postpositions, exclamations), idioms, reduplications, formulaic expressions] in news bulletins, in the textbooks of Turkish courses in middle schools are comprised of the textbooks of Turkish courses taught in the $5^{\text {th }}, 6^{\text {th }}, 7^{\text {th }}$ and $8^{\text {th }}$ grades of middle schools accepted by the resolutions of the Board of Education and Discipline dated and numbered 28.05.2018 - 78, and 25.06.2018 12254648 , and published by the Ministry of Education and the list of first most frequently used 2000 elements of vocabulary in news bulletins.

\section{Method}

As a case study, the holistic multiple-case study design was utilized in this research. Case study is an approach that has different forms and is commonly preferred in qualitative research. According to Davey (1990), it is a method in which a case or an incident is studied in-depth and longitudinally. It is a systematic way to describe the case that is the object of the research, to gather detailed data, to analyze the information and to report the results. The holistic multiple-case study design was used because each case was analyzed in a holistic approach and results attained were compared to one another (Yıldırım and Şimşek, 2013, p. 327). Data were gathered by document analysis method, and the content analysis was implemented during the interpretation process of the data.

\section{Results and Discussion}

In textbooks of middle school Turkish courses, students encounter three quarters of the first most frequently used 2000 elements of vocabulary in news bulletins, while they do not come across a quarter of them. Therefore, the probability of experiencing communicational problems in social relationships will increase; because it is possible for people to understand one another exactly and accurately, only when they have a common universe of concepts and language units. For this reason, governments that are aware of the strategic significance of common vocabulary ensure that the language used in national media organs is structured based on the most frequently used elements of vocabulary of the people of that country.

When numerical values that emerge are taken into consideration, the number of language units that are not encountered should decrease as the grade level increases, but this is not the case in the textbooks we have studied. Although, in the qualitative respect, a decrease in the number of unencountered language units in middle school textbooks of Turkish courses is seen from $5^{\text {th }}$ to $7^{\text {th }}$ grades, this decrease is devoid of proportional consistency. However, while the number of 
unencountered elements of vocabulary in $8^{\text {th }}$ grade should be less than other grade levels of middle school, it is remarkable that it is higher than those in $6^{\text {th }}$ and $7^{\text {th }}$ grades. This situation suggests that a formative planning related to enriching the students' vocabulary is not made while textbooks are written.

The Ministry of Education has been carrying out projects at elementary and middle school levels with the objective of adopting a democratic school culture that encompasses basic rights and liberties, engrafting it in the education system, and popularizing democratic culture implementations among the people that constitute the society. However, among the 239 language units that are not included in the textbooks of middle school Turkish courses, the elements of vocabulary mentioned below, which are a part of the conceptual and associative area of the noun phrase culture of democracy appear as a data worth emphasizing.

"aday adayı (candidate for nomination), anayasa (constitution), atama (appointment), basın toplantısı (press conference), başkanlık sistemi (presidential system), denetim (governance), genel başkan (chairperson), genel merkez (headquarters), genel seçim (general elections), hukuki (legal), hükûmet kur- (to form a government), istifa et- (to resign), kabine (council of ministers), katılım (participation), koalisyon (coalition), komisyon (commission), kurultay (congress), milletvekili (member of the parliament), mağdur (injured party), muhalefet (opposition), muhalefet partisi (opposition party), muhalif (opponent), müzakereci (negotiant), oturum (session), oy kullan- (to vote), oy ver- (to vote), oylama (voting), parlamento (parliament), propaganda (propaganda), reform (reform), rejim (regime), sandığa git- (call an election), seçim hükûmeti (election government), seçmen (voter), seçmen kütüğü (voter roll), siyasetçi (politician), vekil (deputy), vesayet (political tutelage), yasa (law), yasa dışı (illegal), yasal (legal)"

Although it is possible to come across these elements of vocabulary that do not exist in the textbooks of middle school Turkish courses in textbooks of social science courses and others, enriching the students' vocabulary through studying words, word groups and phrases, enhancing their world of emotions, thoughts and imagination, providing them with a gusto and awareness of language are among the objectives of the syllabus of Turkish courses. Therefore, these objectives should be accomplished through essays in the textbooks of Turkish courses and studies directed to related achievements. In consequence, the quality and diversity of essays in the textbooks of Turkish courses should be reviewed in order to materialize and amplify culture of democracy. 